\title{
Utilization of Big Data Analysis Through Public Video, Virus Data Cooperation, and Social Media as the Surveillance to COVID-19 in Indonesia
}

\author{
Achmad Maulana Sirojjudin \\ Department of Communication Studies, Faculty of Social and Political Sciences, University of Indonesia \\ (email: achmad.maulana92@ui.ac.id)
}

\begin{abstract}
This article discusses Big Data's use as a surveillance tool for the spread of Corona Virus Disease 2019 (COVID-19), both in Indonesia and the world. In Indonesia, the range of COVID-19 is increasingly sporadic, causing mass panic and Indonesia's geographical characteristics, which will be difficult when this spread could not control quickly. Researchers are conducting several studies to overcome this pandemic, including supervision, features, handling, mobility, patient interaction, treatment evaluation, and the biological structure. These studies become data and lead to Big Data. This article explores how to use Big Data analysis to monitor the spread of COVID-19 as a communication process that reflects mediated communication as a form of mobility and spatial relationships in communication practices. The method used in this article is a literature review and uses meta-synthesis techniques as its analysis. The literature sources used are articles in highly reputable international journals. Based on the reports, various ways to monitor the virus's spread, through public video data, GPS, and social media tracking, trace the patient's movement. Big Data can also provide data collaboration for viruses and pathogens for further research as digital mediated communication is anchored by the diversity of places and the mobility of people, data, and objects.
\end{abstract}

\section{Keywords:}

big data; COVID-19; data cooperation; infectious disease; surveillance

\section{Introduction}

Using Big Data today is not just used to see consumer behavior in marketing; more than that, Big Data can be used in various things such as online journalism (Guo et al., 2016), music production (Arditi, 2019), helping the formation government policies (Cohen, 2014; Yeung, 2017), terrorist tracking (Kraidy, 2018; Strang \& Sun, 2017), risk management (Chakraborty, 2019; D. Wu \& Lambert, 2020), disease diagnostic tools (Simonsen et al., 2016; Zetino \& Mendoza, 2019), innovations in the health sector (Bowman et al., 2020; WitjasPaalberends et al., 2018), biomedical research (Schofield et al., 2019), and mass supervision (Maras \& Wandt, 2019). The data itself is not objective and needs analysis from researchers in various ways (Frith, 2017). After the analysis, the latest data can be used in various ways and for fulfillment in various fields.

Big Data algorithmic analysis can use as a monitoring tool in infectious diseases. This analysis emphasizes that Big Data's function is very relevant to the digital era, providing much data on the internet and cloud storage. In a more profound analysis, the relevance of surveillance through Big Data also connects with the global pandemic crisis, namely COVID-19. From the end of 2019, the potentially deadly coronavirus (called Coronavirus Disease 2019 or COVID-19) in Wuhan, China, spread globally and affected millions of people geographically. In pathological terms, the corona zoonosis virus, originally called 2019- 
$\mathrm{nCoV}$, was first identified in people exposed to seafood or the wet market (Perlman, 2020). As for the virus itself, the International Committee on Taxonomy of Viruses has named the virus SARS-CoV-2, which officially recognizes this virus as a sister to Severe Acute Respiratory Syndrome (SARS) (Global Biodefense, 2020).

The transmission of COVID-19 to humans describe in several journal articles, one of which is by Henwood, who describes that COVID-19 has an incubation time of between 2 and 10 days by spreading through droplets and sticking to contaminated surfaces or hands. There may be different patterns of transmission not yet known. There are various disinfectants available to disinfect surfaces containing COVID-19 in them (Henwood, 2020). Moreover, it has been noted that other coronaviruses (e.g., SARS and MERS) can survive on non-living surfaces such as metal, glass, or plastic for up to 9 days but can be efficiently deactivated by surface disinfection (Kampf et al., 2020).

Research on COVID-19 was also carried out by observing the epidemic curve's growth rate and estimating serial intervals (SI). The study results indicate SI COVID-19 may be shorter than the incubation period; the pre-symptomatic transmission can occur immediately after infection. It implies a small portion of the transmission cannot be prevented simply by isolating cases of symptoms because when contact tracing is carried out, they may already be contagious and produce secondary cases. Therefore, effective quarantine of suspected (and other possible) cases and close contact, and timely contact tracking, are crucial in the success of outbreak mitigation (Zhao et al., 2020). It raises concerns, especially in Indonesia, which has heavy air traffic and means people's mobility is relatively high. From these interactions, COVID-19 can be easily transmitted to people around the virus carrier.

The COVID-19 case in Indonesia created debates that polarized concerning the government's capacity to provide adequate health facilities. Of course, the spread of COVID-19 needs to be prevented before the country's condition gets worse than before. As a country with several start-ups that utilize digital technology, Indonesia should also use information technology and Big Data as a preventive and curative response to the pandemic by adapting the same technology.

On this basis, the Indonesian government needs to take various steps to prevent this spread from continuing and becoming more sporadic. One way to avoid this is to maximize the use of Big Data. In some studies, using Big Data can help monitor the transmission of infectious diseases. One of its applications is to monitor patients with influenza, which makes many people worry about differentiating between flu and COVID-19. In the experiments to analyze influenza cases, the data obtained were only using granular thermometer-based data. It shows that influenza forecasts can increase when the amount of readings data and devices increases. This step can also use mobile application data to record symptoms at an hourly or daily rate. This technology can be extending to focus on finding "directionsetting" by populations and regions, for example, the elderly and children vulnerable to COVID-19, to provide indicators for influenza at the critical activity. These inventions would help inform more local influenza forecasting efforts (for example, though this has not yet happened, influenza forecasting work in the future is expected to concern influenzarelated outcomes. It could also determine the use of thermometer-based data to detect non-influenza outbreaks. This work will help provide a prompt warning for influenza outbreaks and other fevers (Miller et al., 2019).

Rapid advances in analytical technology and increased opportunities to mine easily accessible data sets provide attractive prospects for advancing knowledge and improving clinical care. Observation data can improve 
disease understanding (Bowman et al., 2020). Seeing the function of Big Data can become hypernudge-a compelling character because it is networked, updated continuously, dynamic, pervasive, and flexible-and a monitoring tool, the Indonesian government, may use this Big Data to analyze patterns of positive patient interaction with COVID-19. Big Data promises to fully utilize the enormous amount of data by supporting the supervisory function, primarily disease surveillance and health care, as a supporter of clinical decisions and personal health care management (J. Wu et al., 2017). This study shows a policy can finally create this oversight function with extensive use and acceleration of Big Data analytic techniques (Cohen, 2014; J. Wu et al., 2017; Yeung, 2017). The analysis will build through a literature review from various sources with similar characteristics to the COVID-19 case by conducting a meta-synthesis - the thorough systematic review and integration of discoveries from research-to obtain the case link's critical function. The article helps health institutions and the government build an effective way to eradicate the pandemic.

\section{Methods}

The methodology in the discussion of this article uses a Literature Review. This article discusses making a report based on the principles he made about the accumulated and cumulative knowledge in this Literature Review method. In principle, researchers from existing journal articles build on intelligence developed by previous research conducted by other researchers (Nakano \& Muniz Jr., 2018). This method is suitable for building knowledge about what Big Data can do in various fields of research. So, there needs to be an effort to build up previous Big Data experience to build research like never before. A helpful literature review is capable of building and supporting the approval of new articles. The statement of the problem described for the required Literature Review, the questions by the questions, assessment of existing work, and generate of new knowledge from the process to be built based on a new conceptual, and will contribute to the creation of unique articles with the proper connection (Leary \& Walker, 2018).

In this article, a thorough systematic review is carried out as in meta-synthesis. Relevant data are collected manually. Also, through a thorough systematic review, relevant data is collected manually through a paper search examination based on a predefined set of terms, via available electronic databases, before scanning each title and abstract of the work taken to determine its relevance. The applied methodology is further detailed in a future subsection. Go through a paper search examination based on a predetermined set of terms, via available electronic databases, before skimming the titles and abstracts of each work taken to determine its relevance.

\section{Databases and Terms}

The search method is databaseoriented and includes all published journal and conference articles extracted from four major bibliographic databases related to the interdisciplinary major, specifically Elsevier; Oxford University Press; Taylor and Francis; Sage Publications; and Springer. The search focused on sampling analytics frameworks and Big Data usage and identified the perceived challenges associated with Big Data aspects: volume, variety, and speed. For this purpose, several terms have been searched: "Big Data Analytics," "Big Data in the Medical Issues," and "Big Data for Infectious Disease" as synonyms describing the same search area.

\section{Inclusion and Exclusion Rules}

The criteria applied to identify relevant studies that meet the requirements of the research questions among those collected from electronic databases are mainly: 
1. Articles must be published between 2016 and 2020.

2. This article must be written in English.

3. Articles should involve processing steps associated with the attached task of Big Data analysis in infectious disease surveillance.

The article should discuss Big Data analysis-related challenges based on the four V's of Big Data (volume, variety, velocity, and veracity). The $4 \mathrm{~V}$ 's associated with Big Data are exclusively considered on the following basis: The value dimension, as defined by Sapountzi and Psannis (2018), stands as the process adopted for extracting valuable insights and information from data. Besides, Zeng et al. (2010) devised different techniques to extract value from data, such as machine learning, data mining, statistics, optimization, and decision support analysis, which are also applied.

The database list (Table 1) shows the number of research articles used in this article. Some articles which the researcher feel have sufficient relevance to describe other research articles will be discussed in the Literature Review section. This section will look at the findings, strengths, concepts that can use in the future, and weaknesses.

Table 1.

\begin{tabular}{ccc}
\multicolumn{2}{c}{ Number of Research per Database } \\
\hline Electronic Database & $\begin{array}{c}\text { Number } \\
\text { of Papers } \\
\text { Identified in } \\
\text { Search }\end{array}$ & $\begin{array}{c}\text { Number of } \\
\text { Papers Meeting } \\
\text { Inclusion } \\
\text { Criteria }\end{array}$ \\
\hline Elsevier & 10 & 4 \\
Emerald Publishing & 11 & 3 \\
Oxford University & 7 & 5 \\
Press & 7 & 5 \\
Taylor and Francis & 30 & 18 \\
Sage Publications & 11 & 5 \\
Springer & &
\end{tabular}

Source: Author

\section{Literature Review}

In building a more comprehensive understanding, there are several relevant literature reviews used to analyze this case. The literature used in this article is an article sourced from highly reputable international journals. Of the several materials utilized as a reference, most analyzed cases of surveillance of infectious diseases. First, Bansal et al. (2016) write the paper, which provides data analysis for monitoring and modeling infectious diseases. The article results are that researchers introduce representation, bias, validation, and volatility, and the need for statistical analysis and hypothesis-driven analysis. Researchers consider the extensive Big Data definition with public health, which includes information of patients collected from huge-volume health records and surveillance systems as digital trace mining from social media, internet search, and mobile phone logs (Bansal et al., 2016). Overall, Bansal et al. consider the bright future of the Big Data revolution that could improve the timeliness and granularity of provided epidemiological records by adding hybrid systems to improve forecasting accurate infectious disease models.

In the other case, experiments in clinical surveillance and evaluation of Ebola cases in vaccine trials during the epidemic. In these experiments, doctors have biased results in malaria rather than Ebola. Data analysis tells the feasibility of conducting Ebola surveillance for vaccinated people during the Ebola epidemic. It also introduces altered case definitions and management algorithms to distinguish vaccine reactions of the initial Ebola symptoms that might reduce unnecessary Ebola evaluation among vaccinated people during an Ebola outbreak (Conteh et al., 2018). The thing to note is that researchers' vaccination to those suspected of contracting Ebola is more curated and more effective. Reducing laboratory analysis time is based on diagnosis analysis through data collected for analysis through data networks.

Big Data analysis also can utilize surveillance tools through video. Research about Big Data analytics for video surveillance 
found that the overall development of Big Data analysis techniques for video surveillance is possible. This research explores various research opportunities available in the handling, analysis, and storage of video data. This advantage could process video images as analysis. Extending this video data drives the improvement of video processing technology to maneuver large amounts of data efficiently. Video technology needs to be improved to handle vast amounts of data. With the exponential broadening of video data, the capability and efficiency of manipulating data from video analysis algorithms ought to be improvised with exponential speed. Otherwise, the current excellent methodology will inevitably fail. There are many challenges, and Big Data's scope for video analysis will be the most critical for future research (Subudhi et al., 2019).

In Big Data analysis, another important thing is the data source itself. Cases of COVID-19 occur in the digital age, where using Social Networking Sites (SNS) is widespread. From the SNS, data can be collected until finally analyzed for specific purposes. In this case, it is used for the prevention of infectious diseases. In another research utilize SNS has transversed the role of personality in predicting usage. In the study, the demographic variables strongly correlated with the character, which are significant prognosticators. Future research could determine which five personality factors are associated with information interchange. The results tell us that higher trust encourages information reception, while social connections promote information delivery. In contrast to previous findings, this study shows that confidence does not affect information provision when social relationships are including in the model (Sinapuelas \& Ho, 2019).

Besides using smartphones, when we use Social Networking Sites (SNS), some data will also be connected to Big Data, creating digital footprints, which can later be analyzed by algorithmic analysis for specific purposes (Al-Saggaf \& Islam, 2015). Furthermore, the data collected, especially about our health conditions, can be used in Play Store and App Store applications. From there, we can see, and even the application can calculate and analyze our condition while facing issues (Sinapuelas \& Ho, 2019; Subudhi et al., 2019). Data like this are essential for analyzing the spread of COVID-19 and how patients are treated. Big Data offers an alternative way to take things to the next level, never before. Also, data obtained through satellites, public cameras, websites, Google Search Engines, Google Analytics, smartphone applications, financial technology (fintech), streaming platforms (AlSaggaf \& Islam, 2015; Arditi, 2019; Bansal et al., 2016; Couldry \& Mejias, 2019; Frith, 2017; Leal et al., 2019; Madianou, 2019; Madianou \& Miller, 2013; Miller et al., 2019; Nielsen \& Schrøder, 2014; Sinapuelas \& Ho, 2019; Singh, 2019; Strang \& Sun, 2017; Subudhi et al., 2019; J. Wu et al., 2017).

It is crucial to monitor the mobility of people who already have a positive corona status. Supervision can be done by analyzing public cameras and locations received on their smartphones and looking at these people's affordability when interacting and with whom they interact. When a person who already has a positive COVID-19 status goes to a place, then the place visited by that person is getting ready for all the possible possibilities. It is essential to see how they relate to each other in building a complete understanding of the COVID-19 problem and policy-making through Big Data analysis as a preventive measure for the Indonesian government in suppressing the spread of COVID-19 before it becomes more widespread than now and become worse.

\section{Results}

\section{Data Interconnectivity}

Linear to the concept, researchers point out that social media is becoming increasingly 
important to gather users' data, based on comparative cross-country surveys in eight countries. Essentially, any activity we do on the internet is a process of datafication of our virtual universe activities (Huiberts, 2020; Poom et al., 2020). Datafication has been done earlier on the many smartphones that support GPS and other GPS devices to raise new possibilities to let us enter vehicle trajectory data that contains reliable information. The information comprises a specific person's travel behavior (e.g., Departure time, route, destination-origin) and the appropriate travel activity (e.g., Delays, driving speed, actual travel time). Besides, in everyone's smartphone settings, the device requests access to some data; this is collected and leads to Big Data (Hu et al., 2019). Also, in Indonesia, GPS can track vehicles installed in the vehicle or the driver's smartphone (Nugroho et al., 2019; Wijaya et al., 2010). Overall, this study may serve as a starting guide for those wishing to tackle social media data, location-based data, CCTV data analysis by serving them to get a clear picture of the processing steps involved in data interconnectivity and Big Data developed technology applicable to each step from the pipe data. Considering the promising results of this study, they provide a conceptual framework related to the Big Data pipeline and the Social Data analysis process.

\section{Big Data in Surveillance Purposes}

Developing cyberinfrastructure has enabled surveillance on a microscopic scale, in part, due to the collection, creation, and analysis of Big Data inside the structure of contemporary capitalism. Second, equitable development has created new opportunities to fight and avoid the exact structure of surveillance and control. The surveillance practice oversight has typically seen today's quantity of data tracked and stored, its creation, and the reality we now voluntarily provide through the standard technology and media we use. Big Data leakage has been circulating as one of Big Data analysis software's primary data collection methods. The software usage concludes that inspiration about Big Data practices also unfolds in a vaguely known way (Skare, 2019). Surveillance carried out through algorithmic data analysis is also obtained from various sources, such as social media, smartphone applications, websites, cloud storage, and public CCTV installed. Detection of abnormal events and tracking based on traffic video surveillance trajectories, the concept of data fields used to find relationships between spatial points in the data space and group them into groups based on their reciprocal interactions (Athanesious et al., 2019). The analysis can use metadata, transcripts, visual contents, and soundtracks through the video to detect human activity. Different researchers also examine social omen processing where nonverbal cues, such as body postures, facial expressions, vocal characteristics, and movements, are explored to investigate behavior (Shao et al., 2018).

A typical weakness of most video processing practices is their inability to capture solid scenes. With the increasing frequency of moving objects at the stage, performance in supervision will decrease significantly. The surveillance can see the changes in view, the thickness of people, the appearance of ambiguous body parts (e.g., Some parts of an individual object in the display may be similar to other nearby objects), adding complexity. Surveillance carried out on many people in the Big Data analysis is possible because of its nature, which can accommodate large amounts of data. Hence, multi-camera systems are used to surveillance large areas, such as tracking vehicles traveling through the city road network. Object paths in several cameras are received by geometric projection to optimize the trajectory (Subudhi et al., 2019). Some researchers in Indonesia can build a system of analysis for detecting motion for tracking through CCTV (Adhinata et al., 2020; Sagala 
et al., 2020). Also, users get real-time motion detection information for human objects (Orisa et al., 2019). It recently proposed integrating several data sources to improve and monitor the resulting data, leading to better semantic data analysis. The growth of video data drives video processing technology to efficiently handle large amounts of data and prepare the infrastructure to utilize this Big Data as a COVID-19 prevention tool.

Furthermore, social media brings a new dimension to health care by providing a common channel for health care professionals, patients, and the public to communicate about health issues, potentially improving health outcomes. It is a powerful tool for social interaction and continuing education and facilitates collaboration between users (Wong et al., 2020). The data mining beyond topic identification and also consider growing trends in their research paper by proposing a multi-modal social event tracking and evolution framework by mining social media data, especially in Indonesia (Asih et al., 2020; Hasri \& Santosa, 2018; Massie, 2019; Wong et al., 2020).

\section{Big Data in the Medical Issues}

Big Data practices and epistemology expected to help improve efficiency and effectiveness in fostering healthy living habits/ practices, to enable more precise predictions and better disease prevention, and to help the development of medical interventions, both from a commercial perspective and from a public health perspective (Madjido et al., 2019; McMahon et al., 2019). Artificial intelligence and machine learning techniques are helpful to accelerate these benefits and fully 'open up large data values.' Rapid advances in analytical technology and increased opportunities to mine easily accessible data sets provide attractive prospects for advancing knowledge and improving clinical care. Personal data is information relating to identified patients or can be identified as playing an essential role in this effort (Bowman et al., 2020; Leal et al., 2019; McMahon et al., 2019).

In the context of medical surveillance of diseases with high transmission rates, infectious disease control data has always been a surveillance system that tracks disease, pathogens, and clinical outcomes (Bansal et al., 2016; Simonsen et al., 2016). The wealth of information promised by Big Data, combined with developing new analytical and modeling tools, will explain the complicated details of transmitting infectious diseases that have remained obscured by traditional data analysis. It is natural to integrate multiple data sources to make a more accurate model. However, the selection of additional information to improve predictions-drug responses from disease-affected cell lines-is related to many factors, including phenotypes, environmental exposure, drugs, and chemical molecules, to determine which factors are more causative (Güvenç Paltun et al., 2019). In practice in Indonesia, the researchers gather health information systems that include drug usage, therapeutic class, pathogen sample, and surveillance in a specific district or city (Madjido et al., 2019; Wahyuri et al., 2019).

This data helps the medical world shape responsive actions and speed of vaccine discovery in new types of pathogens (Conteh et al., 2018; Diallo et al., 2019; Miller et al., 2019). As in COVID-19, which has a family similarity with SARS and MERS. SARS and MERS data were used to identify COVID-19 pathogens, and researchers in various medical fields eventually discovered and revealed a virus called SARS-CoV-2. In this pandemic, without collaboration between researchers with real-time data sharing, it will take a long time to move virus samples from one country to another.

\section{Data Cooperation within Big Data}

The concept of cooperation in wireless communication networks has attracted significant attention from both academia and 
industry because it can effectively overcome the limitations caused by user mobility and scarcity of network resources. The concept was adopted from social sciences and economics to form a significant research area in wireless communication networks. The potential benefits of cooperation in wireless communication networks include increased reliability and overall reduced service costs and energy consumption and support for seamless service provision (Zhuang \& Ismail, 2012). Data in other systems can be communicated to other systems to improve mobility effectiveness and efficiency through this. Especially in COVID-19, when mobility severely disrupts, data collaboration via the internet is an effective way to keep moving in overcoming this pandemic.

Data cooperation concerning data activism only exists in the political economy of personal data and its socio-technical arrangements carried out in an analysis by data agencies (e.g., institutions, companies, and countries) and community participation. Collaboration between data agencies creates the ability to make appropriate choices regarding the analyzed issue (Lehtiniemi \& Haapoja, 2020). The production of diplomatic knowledge through diplomatic texts as data can be understood as the primary fruit of many diplomatic practices, playing a vital role in the country's constitution in the context of other international actors, their own country, and their interlocutors (de Orellana, 2019). Countries must urge to increase cooperation to solve various problems, strengthen research, and enrich international data (de Orellana, 2019; Mann \& Daly, 2019; Roy, 2019). Therefore, this data collaboration is a form of geo-politics. After all, data collection is related to politics, especially international relations, which is influenced by geographical factors and sociopolitical because it presents a connection between politics (policy analysis and decisions) social factors as affected by the COVID-19 crisis.

\section{Discussion}

In the health sector, the ideal surveillance system represents the population, is flexible, resilient, and economical, with timely reporting and validation of the outputs. Full situational recognition requires the availability of multiplex streams of monitoring data that seize patient and severe clinical outcomes (emergency visits, death certificates, and hospitalizations) and laboratory-based information (confirmed cases, serological findings, and genetic sequences) (Conteh et al., 2018; Simonsen et al., 2016). In Indonesia, the aggravation data has been able to be collected in a system. Indonesian health information researchers have shown their interest in using the latest approach in exploring health information through Big Data and the internet of things in their practice. The most common research topics are hospital information systems, electronic medical records, mHealth, telemedicine, and primary health care information systems (SIMPUS) (Madjido et al., 2019). Health data can also be analyzed in a dataset containing five attributes: drug name, therapeutic class, district/city, sample category, and drug surveillance evaluation (Wahyuri et al., 2019). A new surveillance approach using large data streams from crowdsourcing, internet search, and social media has suggested utilizing in parallel. The form of the process carried out in data communication is a new phenomenon of mediated digital communication. There is a tremendous possibility of using massive volumes of unknown electronic medical records to advise the results of contagious diseases (deaths, doctor visits, and hospitalizations) and designs of absorption of drugs, vaccines, and related adverse situations.

Media and communication studies have demonstrated remarkable agility for methodological innovation in the past, not least because the inflexibility of institutionalization into competing camps is less pronounced here than elsewhere in the social sciences (Helles 
\& Ørmen, 2020; Xie, 2021). Recognizing the potential of Big Data to support many kinds of explanations, perhaps it could repeat that success. The benefits of doing so will not only be methodological dividends to the field: A critical understanding of Big Data as a broader social phenomenon can only benefit from an informed understanding of the potential and alternative possibilities for explanation and uses that it can imply. When someone tests positive for COVID-19 in the Indonesian context, Big Data can analyze anyone who has made close contact with infected people-by using locationbased closeness between patients and other users significantly - and use warnings to the authorities to find these people. In this way, the government can shorten the State Intelligence Agency's (BIN) tracking method. Thus, sometimes, Big Data is a tool to produce regulations to design personal but collective communications that are persuasive and profitable.

Here, there is a case prediction from a statistical analysis of events in Indonesia, and it was concluded that before Ramadan, infected people could reach 700,000 people (Cahya, 2020). Tracking data such as the period of patient recovery while in care, it is also helpful to determine how much more hospital isolation room capacity will be needed when increasing patients' numbers. From here, it provides the best decision supported by data analysis. Using Big Data can also be used to see the distribution pattern of COVID-19. This analysis is carried out by looking at Depok's first case and has spread to various regions in Indonesia. The results obtained can be a step to anticipate positive cases of COVID-19 in adjacent areas, including increasing the readiness of local medical facilities and preparing for the worst possible scenario. For more in-depth data analysis, the government needs to collaborate with other countries to analyze and adapt it to the Indonesian context.

A study involving CCTV in Indonesia was conducted by Adhinata et al. (2020). In this experiment, CCTV can be a tracking tool and detect the number of people. In addition, Sagala et al. (2020) research uses motion detection to reduce CCTV recording data size. Their research found that the object detection system in visual data can detect objects with a precision level of $79.87 \%$ with a fast image processing speed with an average of about 38.67 images per second. This CCTV video analysis in a study can be analyzed through motion detection applications applied to surveillance cameras that monitor the surrounding environment's security. The application has been proven to detect human objects both day and night. Any detected object movements can be stored in a database on the webserver side. Users get real-time motion detection information for human objects (Orisa et al., 2019). In Big Data analysis related to tracking COVID-19 patients, Indonesia can conduct tracking through this public CCTV. Although CCTV in Indonesia is still not evenly distributed in some areas, it can still be used for areas with a high COVID-19 infection rate, namely in big cities in Indonesia. Big cities in Indonesia also have adequate CCTV infrastructure.

Besides CCTV, tracking can also be done through location-based tracking. Over ten years ago, GPS-based vehicle tracking was possible. The project carried out by Wijaya et al. (2010) made a GPS-based vehicle tracking device via a cellular network. This tool is part of the vehicle tracking system. This tool will respond to commands sent by the tracker via SMS. This device contains three parts. A microcontroller is part of the control, GPS that provides position information, and a GSM modem used to send or receive messages. These parts will work together to process all messages sent by the tracker. Then the server will get information about the position in longitude, latitude, date, and time. Nugroho et al. (2019) carried out the same project, tracking four-wheeled vehicles in Yogyakarta. These projects indicate that it is possible to track and monitor COVID-19 
patients. Strengthening Big Data analysis is one of the critical jobs for implementing tracking on a broader scale. Strengthening the analysis based on these projects is helpful, not only for COVID-19 but also for surveillance in other fields. Moreover, the use of social media as a form of tracking based on location and interaction can also be carried out in Indonesia, considering that social media users in Indonesia are vast (Asih et al., 2020; Hasri \& Santosa, 2018; Lim, 2017; Yulianto \& Layona, 2017).

The government's stride can be seen as transparency steps taken by the government regarding this pandemic. Using Big Data can change this emergency to be more controlled. In the geographical context, Indonesia's territory, which consists of so many islandssome regions have inadequate access to transportation-makes access to medical services and distribution of medicines take quite a long time. This concern arises when prevention is ineffective and efficient, using Big Data in future outbreaks or epidemics. First, communication and integration with more allinclusive public health responses are feasible and needed, not only for coordination of supervision but also to evade interposing with different response activities. Second, the case handler that has taken place, then the existing data, is referred for evaluating COVID-19. Thus, in the fading epidemic, the burden of COVID-19 monitoring and assessment can be managed. Third, analytic strategies using adjusted case definitions and case management algorithms to differentiate vaccine effects from COVID-19 traits that might occur in vaccinated participants before the onset of the disease appear to be a sensible proposition to restraining unnecessary exposure to COVID-19 facilities.

\section{Conclusion}

Big Data analytics can be an innovative form of communication requiring people to communicate effectively to interpret which findings are meaningful, turn data analysis into meaningful narratives, and work with stakeholders to act on data. It includes various general knowledge processing and video image analysis fields, particularly text detection, human activity detection, crowd tracking, and Big Data-based multi-camera surveillance. It can also examine the social cues where nonverbal cues, such as posture, facial expressions, vocal characteristics, gestures, were explored to investigate behavior. Developing schemes to process extensive surveillance video data to observe actions and activities in sensitive geographic areas can also be done through Big Data analysis. The wealth of information promised by Big Data, combined with developing new analytical and modeling tools, will help shed light on the intricate details of infectious disease transmission dynamics that have remained obscured by traditional data analysis. It is natural to integrate multiple data sources to create a more accurate model.

This era of social media brings a new dimension to health care by providing a common channel for health care professionals, patients, and the public to communicate about health issues, potentially improving health outcomes as the form of mediated communication. It is a powerful tool for social interaction and continuing education and facilitates collaboration between users. Besides, through social media data mining and the use of smartphones, location history can be viewed. So that smartphone users can be seen where they are traveling. Preventive measures include essential matters, especially in Indonesia, which has an archipelago-specific country. In some places, transportation access is so limited to travel. If the spreading chain is not broken, these conditions will further aggravate the impact of COVID-19 in Indonesia.

This article also opens up a new picture and provokes empirical research into Big Data with various data sources simultaneously and integrated. Thus, to produce sharp data 
analysis according to the issue, the analyses of various platforms need to be utilized, such as satellites, public cameras, websites, Social Networking Sites, Google Search Engines, Google Analytics, smartphone applications, financial technology (fintech), streaming platform, notes on specific issues (medical records), and other various sources.

Indonesia needs to use Big Data analysis as a monitoring step before it is too late. Indonesia needs to deploy cooperation on data to produce a wealth of data other than those obtained through Big Data spread on the internet and cloud storage with such conditions. Besides, the government analyzed data through algorithmic analysis can broadly picture what is being watched and the prevention of viral things, both pandemic and mass panic dampers, by creating appropriate and effective policies for the community and by the social conditions of the community, because the nature of Big Data has a powerful nature (hypernudge) to determine policy. Data cooperation in certain conditions is a form of diplomacy carried out by the state government, benefitting the two countries cooperating. Based on that, Big Data has a positively beneficial dimension, which is the nature of cooperation.

\section{References}

Adhinata, F. D., Ikhsan, M., \& Wahyono, W. (2020). People counter on CCTV video using histogram of oriented gradient and Kalman filter methods. Jurnal Teknologi Dan Sistem Komputer, 8(3), 222-227. https:// doi.org/10.14710/jtsiskom.2020.13660

Al-Saggaf, Y., \& Islam, M. Z. (2015). Data Mining and Privacy of Social Network Sites' Users: Implications of the Data Mining Problem. Science and Engineering Ethics, 21(4), 941-966. https://doi.org/10.1007/ s11948-014-9564-6

Arditi, D. (2019). Music Everywhere: Setting a Digital Music Trap. Critical Sociology, 45(4-5), 617-630. https://doi. org/10.1177/0896920517729192
Asih, D., Teofilus, Sutrisno, T. F. C. W., \& Yoana, C. (2020). The effectiveness of social media based on photo and video sharing towards online purchase intention. Jurnal Siasat Bisnis, 24(2), 179-186. https://doi. org/10.20885/jsb.vol24.iss2.art7

Athanesious, J. J., Chakkaravarthy, S. S., Vasuhi, S., \& Vaidehi, V. (2019). Trajectory based abnormal event detection in video traffic surveillance using general potential data field with spectral clustering. Multimedia Tools and Applications, 78(14), 19877-19903. https://doi.org/10.1007/s11042-019-7332-y Bansal, S., Chowell, G., Simonsen, L., Vespignani, A., \& Viboud, C. (2016). Big Data for Infectious Disease Surveillance and Modeling. Journal of Infectious Diseases, 214(suppl 4), S375-S379. https://doi. org/10.1093/infdis/jiw400

Bowman, L., Baras, A., Bombien, R., Califf, R. M., Chen, Z., Gale, C. P., Gaziano, J. M., Grobbee, D. E., Maggioni, A. P., Muse, E. D., Roden, D. M., Schroeder, S., Wallentin, L., \& Casadei, B. (2020). Understanding the use of observational and randomized data in cardiovascular medicine. European Heart Journal, 1-8. https://doi.org/10.1093/ eurheartj/ehaa020

Cahya, G. H. (2020). COVID-29 “could infect some 70,000" before Ramadan. In The Jakarta Post (p. 4).

Chakraborty, G. (2019). Evolving profiles of financial risk management in the era of digitization: The tomorrow that began in the past. Journal of Public Affairs. 20(2). https://doi.org/10.1002/pa.2034

Cohen, J. E. (2014). Studying Law Studying Surveillance. Surveillance \& Society, 13(1), 91-101. https://doi.org/10.24908/ ss.v13i1.5160

Conteh, M.-A., Goldstein, S. T., Wurie, H. R., Gidudu, J., Lisk, D. R., Carter, R. J., Seward, J. F., Hampton, L. M., Wang, D., Andersen, L. E., Arvay, M., Schrag, S. J., Dawson, P., Fombah, A. E., Petrie, C. R., 
Feikin, D. R., Russell, J. B. W., Lindblad, R., Kargbo, S. A. S., Mahon, B. E. (2018). Clinical Surveillance and Evaluation of Suspected Ebola Cases in a Vaccine Trial During an Ebola Epidemic: The Sierra Leone Trial to Introduce a Vaccine Against Ebola. The Journal of Infectious Diseases, 217(suppl_1), S33-S39. https:// doi.org/10.1093/infdis/jiy061

Couldry, N., \& Mejias, U. A. (2019). Data Colonialism: Rethinking Big Data's Relation to the Contemporary Subject. Television \& New Media, 20(4), 336-349. https://doi.org/10.1177/1527476418796632

de Orellana, P. (2019). Retrieving how diplomacy writes subjects, space and time: a methodological contribution. European Journal of International Relations, 2(2), 469-494. https://doi. org/10.1177/1354066119868514

Diallo, A. O., Kiemtoré, T., Bicaba, B. W., Medah, I., Tarbangdo, T. F., Sanou, S., Soeters, H. M., Novak, R. T., \& Aké, H. F. (2019). Development and Implementation of a Cloud-Based Meningitis Surveillance and Specimen Tracking System in Burkina Faso, 2018. The Journal of Infectious Diseases, 220(Supplement_4), S198-S205. https:// doi.org/10.1093/infdis/jiz376

Frith, J. (2017). Big Data, Technical Communication, and the Smart City. Journal of Business and Technical Communication, 31(2), 168-187. https://doi. org/10.1177/1050651916682285

Global Biodefense. (2020). COVID-19 I SARS-CoV-2 Coronavirus Portal. https:// globalbiodefense.com/novel-coronaviruscovid-19-portal/

Guo, L., Vargo, C. J., Pan, Z., Ding, W., \& Ishwar, P. (2016). Big Social Data Analytics in Journalism and Mass Communication. Journalism \& Mass Communication Quarterly, 93(2), 332-359. https://doi. org/10.1177/1077699016639231
Güvenç Paltun, B., Mamitsuka, H., \& Kaski, S. (2019). Improving drug response prediction by integrating multiple data sources: matrix factorization, kernel and network-based approaches. Briefings in Bioinformatics, 00(November), 1-14. https://doi.org/10.1093/bib/bbz153

Hasri, M. I. A., \& Santosa, P. B. (2018). The use of Location Based Instagram Data for Tourism Potential Analysis in Kabupaten Gunung Kidul. JGISE: Journal of Geospatial Information Science and Engineering, 1(1). https://doi.org/10.22146/jgise.38469

Helles, R., \& Ørmen, J. (2020). Big data and explanation: Reflections on the uses of big data in media and communication research. European Journal of Communication, 35(3), 290-300. https:// doi.org/10.1177/0267323120922088

Henwood, A. F. (2020). Coronavirus disinfection in histopathology. Journal of Histotechnology, 00(00), 1-3. https://doi.or $\mathrm{g} / 10.1080 / 01478885.2020 .1734718$

Hu, X., Yuan, Y., Zhu, X., Yang, H., \& Xie, K. (2019). Behavioral responses to preplanned road capacity reduction based on smartphone GPS trajectory data: A functional data analysis approach. Journal of Intelligent Transportation Systems, 23(2), 133-143. https://doi.org/10.1080/1547245 0.2018 .1488133

Huiberts, E. (2020). Watching Disaster News Online and Offline: Audiences Experiencing News about Far-away Disasters in a Postbroadcast Society. Television \& New Media, 21(1), 41-59. https://doi.org/10.1177/1527476418821328

Kampf, G., Todt, D., Pfaender, S., \& Steinmann, E. (2020). Persistence of coronaviruses on inanimate surfaces and their inactivation with biocidal agents. Journal of Hospital Infection, 104(3), 246-251. https://doi. org/10.1016/j.jhin.2020.01.022

Kraidy, M. M. (2018). Terror, Territoriality, Temporality: Hypermedia Events in 
the Age of Islamic State. Television $\mathcal{E}$ New Media, 19(2), 170-176. https://doi. org/10.1177/1527476417697197

Leal, L. G., David, A., Jarvelin, M.-R., Sebert, S., Männikkö, M., Karhunen, V., Seaby, E., Hoggart, C., \& Sternberg, M. J. E. (2019). Identification of disease-associated loci using machine learning for genotype and network data integration. Bioinformatics, 35(24), 5182-5190. https://doi.org/10.1093/ bioinformatics/btz 310

Leary, H., \& Walker, A. (2018). Meta-Analysis and Meta-Synthesis Methodologies: Rigorously Piecing Together Research. TechTrends, 62(5), 525-534. https://doi. org/10.1007/s11528-018-0312-7

Lehtiniemi, T., \& Haapoja, J. (2020). Data agency at stake: MyData activism and alternative frames of equal participation. New Media \& Society, 22(1), 87-104. https:// doi.org/10.1177/1461444819861955

Lim, M. (2017). Freedom to hate: social media, algorithmic enclaves, and the rise of tribal nationalism in Indonesia. Critical Asian Studies, 49(3), 411-427. https://doi.org/10 .1080/14672715.2017.1341188

Madianou, M. (2019). TheBiometric Assemblage: Surveillance, Experimentation, Profit, and the Measuring of Refugee Bodies. Television \& New Media, 20(6), 581-599. https://doi.org/10.1177/1527476419857682

Madianou, M., \& Miller, D. (2013). Polymedia: Towards a new theory of digital media in interpersonal communication. International Journal of Cultural Studies, 16(2), 169-187. https://doi.org/10.1177/1367877912452486

Madjido, M., Espressivo, A., Maula, A. W., Fuad, A., \& Hasanbasri, M. (2019). Health Information System Research Situation in Indonesia: A Bibliometric Analysis. Procedia Computer Science, 161, 781-787. https://doi.org/10.1016/j.procs.2019.11.183 Mann, M., \& Daly, A. (2019). (Big) Data and the North-in -South: Australia's Informational Imperialism and Digital Colonialism.
Television \& New Media, 20(4), 379-395. https://doi.org/10.1177/1527476418806091 Maras, M.-H., \& Wandt, A. S. (2019). Enabling mass surveillance: data aggregation in the age of big data and the Internet of Things. Journal of Cyber Policy, 4(2), 160-177. https://doi.org/10.1080/2373887 1.2019.1590437

Massie, R. G. A. (2019). Akses Pelayanan Kesehatan yang Tersedia pada Penduduk Lanjut Usia Wilayah Perkotaan di Indonesia. Jurnal Penelitian dan Pengembangan Pelayanan Kesehatan, 46-56. https://doi.org/10.22435/jpppk.v3i1.130

McMahon, A., Buyx, A., \& Prainsack, B. (2019). Big Data Governance Needs More Collective Responsibility: The Role of Harm Mitigation in the Governance of Data Use in Medicine and Beyond. Medical Law Review, 0(0), 1-28. https://doi. org/10.1093/medlaw/fwz016

Miller, A. C., Peterson, R. A., Singh, I., Pilewski, S., \& Polgreen, P. M. (2019). Improving State-Level Influenza Surveillance by Incorporating Real-Time SmartphoneConnected Thermometer Readings Across Different Geographic Domains. Open Forum Infectious Diseases. https://doi. org/10.1093/ofid/ofz455

Nakano, D., \& Muniz Jr., J. (2018). Writing the literature review for empirical papers. Production, 28. https://doi. org/10.1590/0103-6513.20170086

Nielsen, R. K., \& Schrøder, K. C. (2014). The Relative Importance of Social Media for Accessing, Finding, and Engaging with News. Digital Journalism, 2(4), 472-489. https://doi.org/10.1080/21670811.2013.8 72420

Nugroho, A. P., Shalih, S. M., Purwantana, B., Sutiarso, L., Radi, Markumningsih, S., Masithoh, R. E., Yun, J. H., Kim, K. U., Yeo, I. C., \& Lee, D. G. (2019). Development of GPS-based Tracking System to Evaluate the Effectiveness of Tillage using Four- 
wheel Tractor. IOP Conference Series: Earth and Environmental Science, 355, 1-26.https:// doi.org/10.1088/1755-1315/355/1/012014

Orisa, M., Auliasari, K., \& El Maghfiroh, R. (2019). TEKNOLOGI MOTION-BASED TRACKINGUNTUKPENGEMBANGAN APLIKASI KEAMANAN. Jurnal Teknologi Informasi Dan Terapan, 4(2), 119-124. https://doi.org/10.25047/jtit.v4i2.69

Perlman, S. (2020). Another Decade, Another Coronavirus. New England Journal of Medicine, 382(8), 760-762. https://doi. org/10.1056/NEJMe2001126

Poom, A., Järv, O., Zook, M., \& Toivonen, T. (2020). COVID-19 is spatial: Ensuring that mobile Big Data is used for social good. Big Data \& Society, 7(2), 1-7. https://doi. org/10.1177/2053951720952088

Roy, N. (2019). Reviewing ocean governance in Asia. Asian Journal of Comparative Politics, 5(4), 437-448. https://doi. org/10.1177/2057891119883127

Sagala, J. P., Candradewi, I., \& Harjoko, A. (2020). Penggunaan Deteksi Gerak untuk Pengurangan Ukuran Data Rekaman Video Kamera CCTV. IJEIS (Indonesian Journal of Electronics and Instrumentation Systems), 10(1), 99. https:// doi.org/10.22146/ijeis.35983

Sapountzi, A., \& Psannis, K. E. (2018). Social networking data analysis tools \&amp; challenges. Future Generation Computer Systems, 86, 893-913. https://doi. org/10.1016/j.future.2016.10.019

Schofield, P. N., Kulka, U., Tapio, S., \& Grosche, B. (2019). Big data in radiation biology and epidemiology; an overview of the historical and contemporary landscape of data and biomaterial archives. International Journal of Radiation Biology, 95(7), 861-878. https://doi.org/10.1080/09553002.2019.1 589026

Shao, Z., Cai, J., \& Wang, Z. (2018). Smart Monitoring Cameras Driven Intelligent Processing to Big Surveillance Video
Data. IEEE Transactions on Big Data, 4(1), 105-116. https://doi.org/10.1109/ TBDATA.2017.2715815

Simonsen, L., Gog, J. R., Olson, D., \& Viboud, C. (2016). Infectious Disease Surveillance in the Big Data Era: Towards Faster and Locally Relevant Systems. Journal of Infectious Diseases, 214(suppl 4), S380S385. https://doi.org/10.1093/infdis/jiw376 Sinapuelas, I. C., \& Ho, F. N. (2019). Information exchange in social networks for health care. Journal of Consumer Marketing, 36(5), 692-702. https://doi.org/10.1108/JCM-122017-2470

Singh, N. (2019). Big data technology: developments in current research and emerging landscape. Enterprise Information Systems, 13(6), 801-831. https://doi.org/10 $.1080 / 17517575.2019 .1612098$

Skare, E. (2019). Digital Surveillance/ Militant Resistance: Categorizing the "Proto-state Hacker." Television $\mathcal{E}$ New Media, 20(7), 670-685. https://doi. org/10.1177/1527476418793509

Strang, K. D., \& Sun, Z. (2017). Analyzing Relationships in Terrorism Big Data Using Hadoop and Statistics. Journal of Computer Information Systems, 57(1), 67-75. https:// doi.org/10.1080/08874417.2016.1181497

Subudhi, B. N., Rout, D. K., \& Ghosh, A. (2019). Big data analytics for video surveillance. Multimedia Tools and Applications, 78(18), 26129-26162. https://doi.org/10.1007/ s11042-019-07793-w

Vavliakis, K. N., Symeonidis, A. L., \& Mitkas, P. A. (2013). Event identification in web social media through named entity recognition and topic modeling. Data $\mathcal{E}$ Knowledge Engineering, 88, 1-24. https:// doi.org/10.1016/j.datak.2013.08.006

Wahyuri, W., Athiyah, U., Puspitasari, I., \& Nita, Y. (2019). Clustering of Drug Sampling Data to Determine Drug Distribution Patterns with K-Means Method :Study on Central Kalimantan Province, Indonesia. 
Journal of Information Systems Engineering and Business Intelligence, 5(2), 208. https:// doi.org/10.20473/jisebi.5.2.208-218

Wijaya, S. P., Christyono, Y., \& Sukiswo, S. (2010). Alat Pelacak Lokasi Berbasis GPS Via Komunikasi Seluler. Transmisi: Jurnal Ilmiah Teknik Elektro, 12(2), 82-86. https://doi.org/https://doi.org/10.12777/ transmisi.12.2.82-86

Witjas-Paalberends, E. R., van Laarhoven, L. P. M., van de Burgwal, L. H. M., Feilzer, J., de Swart, J., Claassen, E., \& Jansen, W. T. M. (2018). Challenges and best practices for big data-driven healthcare innovations conducted by profit-nonprofit partnerships - a quantitative prioritization. International Journal of Healthcare Management, 11(3), 171-181. https://doi.org/10.1080/20479700.2017.1 371367

Wong, A., Ho, S., Olusanya, O., Antonini, M. V., \& Lyness, D. (2020). The use of social media and online communications in times of pandemic COVID-19. Journal of the Intensive Care Society, 175114372096628. https://doi.org/10.1177/1751143720966280

Wu, D., \& Lambert, J. H. (2020). Engineering Systems and Risk Analytics. Risk Analysis, 40(1), 1-7. https://doi.org/10.1111/ risa.13433

Wu, J., Li, H., Lin, Z., \& Goh, K.-Y. (2017). How big data and analytics reshape the wearable device market - the context of e-health. International Journal of Production Research, 55(17), 5168-5182. https://doi.or g/10.1080/00207543.2015.1059521

Xie, Z. (2021). Mobile communicating place and place-inscribed communicative mobilities: Shaping alternative consumer cultures in mobile media communication. Mobile Media \& Communication, 9(1), 51-77. https://doi.org/10.1177/2050157920927451

Yeung, K. (2017). 'Hypernudge'": Big Data as a mode of regulation by design.' Information, Communication $\mathcal{E}$ Society, 20(1), 118-136. https://doi.org/10.1080/13 69118X.2016.1186713

Yulianto, B., \& Layona, R. (2017). An Implementation of Location Based Service (LBS) for Community Tracking. ComTech: Computer, Mathematics and Engineering Applications, 8(2), 69. https:// doi.org/10.21512/comtech.v8i2.3749

Zeng, D., Chen, H., Lusch, R., \& Li, S.-H. (2010). Social Media Analytics and Intelligence. IEEE Intelligent Systems, 25(6), 13-16. https://doi.org/10.1109/MIS.2010.151

Zetino, J., \& Mendoza, N. (2019). Big Data and Its Utility in Social Work: Learning from the Big Data Revolution in Business and Healthcare. Social Work in Public Health, 34(5), 409-417. https://doi.org/10.1080/19 371918.2019.1614508

Zhao, S., Cao, P., Gao, D., Zhuang, Z., Cai, Y., Ran, J., Chong, M. K. C., Wang, K., Lou, Y., Wang, W., Yang, L., He, D., \& Wang, M. H. (2020). Serial interval in determining the estimation of reproduction number of the novel coronavirus disease (COVID-19) during the early outbreak. Journal of Travel Medicine, 1-7.https://doi.org/10.1093/jtm/ taaa033

Zhuang, W., \& Ismail, M. (2012). Cooperation in wireless communication networks. IEEE Wireless Communications, 19(2), 10-20. https://doi.org/10.1109/ MWC.2012.6189408 